lymphoma in a haemophiliac negative for HIV. Serum samples from 1983 and 1984 examined retrospectively also failed to show this antibody. All serum samples were negative for antibody to human $T$ cell lymphotropic virus type I.

Histologically similar extranodal lymphomas have been reported in homosexual men negative for antibody to HIV but with inverted ratios of $T$ helper to suppressor cells. ${ }^{4}$ The aetiology of the lymphomas in such patients is not clear. Congenital and other acquired immune defects are also associated with lymphomas. We previously reported abnormal cell mediated immunity in haemophiliacs with factor VIII concentrate and negative for HIV antibody. ${ }^{5}$ Such defects may have contributed to the pathogenesis of the tumour in our patient.

1 Blattner WA, Saxinger C, Clarke J, et al. Human T cell leukaemia/lymphoma virus-associated lymphoreticular neoplasia in Jamaica. Lancet 1983;ii:61-4.

2 Centers for Disease Control. Revision of the case definition of acquired immunodeficiency syndrome for national reporting-United States. MMWR 1985;34:101-3.

3 Ragni MV, Lewis JH, Bonlempo FA, Spero JA. Lymphoma presenting as a traumatic hematoma in an HTLV-III antibody positive hemophiliac. $N$ Engl $\mathcal{F}$ Med 1985;313:640.

4 Ziegler J, Beckstead J, Volberding J, et al. Non-Hodgkin's lymphoma in 90 homosexual men: relation to generalised lymphadenopathy and acquired immunodeficiency syndrome. $N$ Engl f Med 1984;311:565-70.

5 Madhok R, Gracie A, Lowe GDO, et al. Impaired cell mediated immunity in haemophilia in the absence of HIV infection. BrMed F 1986;293:978-81.

(Accepted 22 December 1986)

University Department of Medicine, Glasgow Royal Infirmary, Glasgow G4 0SF

R MADHOK, MB, MRCP, registrar

G D O LOWE, MD, MRCP, senior lecturer

C D FORBES, DSC, FRCP, reader

Department of Pathology, Glasgow Royal Infirmary

C J R STEWART, MB, registrar

F LEE, MB, FRCPATH, consultant

Correspondence to: Dr Madhok.

\section{Tinel's sign and the carpal tunnel syndrome}

The diagnostic value of Tinel's sign in the carpal tunnel syndrome depends on $(a)$ the wrist position-if dorsiflexed the median nerve becomes stretched and tightens the contents of the carpal tunnel-and $(b)$ the mode of eliciting the sign-thumb pressure, fingertip, or patellar hammer percussion. Stretching the median nerve by the wrist flexion test has also been recommended. We assessed these techniques to determine the best way of eliciting Tinel's sign and its value.

\section{Patients, methods, and results}

Twenty seven patients (19 women, 8 men, aged 22-80 (mean 53)) were examined. Sixteen had unilateral and 11 bilateral carpal tunnel symptoms. Both hands of 14 control patients were also assessed. In all patients we examined both wrists with $(a)$ hyperextension alone, $(b)$ firm thumb pressure once over the carpal tunnel, $(c)$ percussion (two fingers) six times, and (d) multiple percussion, 6-10 beats with a soft "Queen Square" tendon hammer over and proximal to the carpal ligament. A positive response was recorded when the patient complained of distal or proximal paraesthesia, and percussion ceased when this response was obtained. Paraesthesia within 60 seconds with the wrist acutely flexed (wrist flexion test; Phalen's sign) was also assessed. All symptomatic patients and those controls with a positive Tinel's sign underwent electromyography of the median nerve. ${ }^{1}$

In normal wrists repeated firm percussion with a Queen Square tendon hammer produced "awareness" only. In 31 wrists with a hyperaesthetic median nerve hammer percussion resulted in paraesthesia: in 27 this was felt distally, in three proximally, and in one in both directions. Of the 38 hands with symptoms of median nerve compression 33 had the diagnosis confirmed by electromyography. The responses to the various tests are shown in the table. Five paraesthetic hands (five patients) with normal median nerve conduction had a positive Tinel's sign: one patient gave a classical history of carpal tunnel syndrome but was improving when examined, another had thenar wasting and weakness and shoulder-hand syndrome secondary to frozen shoulder, and a third had neurogenic changes in abductor pollicis brevis with normal results on sensory studies.

Seven of the 33 symptomatic hands with electromyographically confirmed median nerve compression at the wrist did not give a positive Tinel's sign on any of the tests; but there was no relation between the severity or duration of symptoms and the absence of Tinel's sign. No patient had complete analgesia in the median nerve distribution. Four of the 14 control patients gave a positive Tinel's sign: two had peripheral neuropathy confirmed on electromyography (one diabetic, one uraemic), one had delivered a baby nine months earlier, and the fourth had been taking prednisone $15 \mathrm{mg}$ daily for a year; these last two patients gave normal results on electromyography.

\section{Comment}

Extending the wrist to tense the contents of the carpal tunnel so that percussion is transmitted to the median nerve may be essential in obtaining Tinel's sign. Also, a broad based Queen Square hammer seemed better than smaller hammers or fingertip or thumb pressure because the whole transverse carpal ligament and several millimetres proximally could be percussed. A false neuroma is sometimes encountered above the carpal ligament, and tension or compression of that area might account for the paraesthesiae, when the wrist is extended or flexed. Five of the symptomatic wrists with a positive Tinel's sign gave normal results on electromyography, but this is common, particularly in mild cases. ${ }^{12}$

Failure to elicit Tinel's sign in electromyographically confirmed carpal tunnel syndrome may have been due to finger percussion, " "gentle tapping" with a patellar hammer, ${ }^{4}$ or failure to appreciate that the carpal tunnel contents are compressed when the wrist is extended. ${ }^{5}$ We therefore conclude that percussing the extended wrist over and immediately proximal to the carpal tunnel using a Queen Square hammer is the simplest and best way to elicit Tinel's sign.

We thank Dr R G Willison, Dr N M F Murray, and Dr K R Mills for allowing us to quote their electromyography results, our colleagues for allowing us to examine their patients, and Miss A Tank for typing the manuscript.

1 Mills KR. Orthodromic sensory action potentials from palmar stimulation in the diagnosis of carpa tunnel syndrome. I Neurol Neurosurg Psychiatry 1985;48:250-5.

2 tunnel syndrome. F Neurol Neurosurg Psychiatry 1985, 2 . Arch Neurol 1967;16:635-41.

3 Stewart JD, Eisen A. Tinel's sign and the carpal tunnel syndrome. BrMed f 1978;ii:1125-6.

4 Gelmers HJ. The significance of Tinel's sign in the carpal tunnel syndrome. Acta Neurochir (Wien) 1979;49:255-8.

5 Brain WR, Dickson-Wright A, Wilkinson M. Spontaneous compression of both median nerves in the carpal tunnel. Lancet 1947;ii:277-82.

(Accepted 18 December 1986)

National Hospitals for Nervous Diseases, Queen Square, London WC1N 3BG

S S MOSSMAN, MB, FRACP, registrar

J N BLAU, MD, FRCP, consultant neurologist

Correspondence to: Dr Mossman.

Sensitivity of Tinel's sign elicited by different methods

\begin{tabular}{|c|c|c|c|c|c|c|}
\hline Method of eliciting Tinel's sign & No tested & Positive sign & $\begin{array}{c}\text { Positive } \\
\text { electromyogram }\end{array}$ & $\begin{array}{l}\text { Positive sign and } \\
\text { electromyogram }\end{array}$ & $\begin{array}{c}\text { Sensitivity† } \\
(\%)\end{array}$ & $\begin{array}{c}\text { False positives } \\
(\%)\end{array}$ \\
\hline $\begin{array}{l}\text { Tendon hammer percussion* } \\
\text { Finger percussion } \\
\text { Wrist flexion } \\
\text { Thumb pressure* } \\
\text { Hyperextension of the wrist }\end{array}$ & $\begin{array}{l}38 \\
38 \\
32 \\
35 \\
38\end{array}$ & $\begin{array}{r}31 \\
19 \\
11 \\
8 \\
2\end{array}$ & $\begin{array}{l}33 \\
33 \\
27 \\
31 \\
33\end{array}$ & $\begin{array}{r}26 \\
16 \\
9 \\
7 \\
7 \\
2\end{array}$ & $\begin{array}{r}79 \\
49 \\
33 \\
23 \\
6\end{array}$ & $\begin{array}{r}16 \\
16 \\
18 \\
13 \\
0\end{array}$ \\
\hline
\end{tabular}

^Performed with the hyperextended wrist.

tSensitivity= positive sign with positive electromyogram $\times 100 /$ positive electromyogram. 